Revista do CESP, Belo Horizonte, v. 37, n. 58, p. 29-44, 2017

\title{
"a alcipe, duplamente": Vasco Graça Moura e o diálogo com a tradição
}

\section{“a alcipe, duplamente": Vasco Graça Moura and the dialog with tradition}

Natália Ubirajara Silva

Rede Municipal de Ensino de Porto Alegre, Porto Alegre, Rio Grande do Sul / Brasil natisil1@gmail.com

Resumo: O presente artigo tem como objetivo analisar elementos da poética de Vasco Graça Moura (1942-2014) a partir do poema "a alcipe, duplamente", presente na antologia Poesia 2001/2005 (2006). Poeta de vertente clássica, Vasco Graça Moura se caracteriza pelo uso abundante das relações transtextuais (conforme a acepção de Gérard Genette) como elemento chave para a interpretação de seus poemas. No poema analisado, destacam-se a intertextualidade (citação, alusão), a arquitextualidade e a hipertextualidade como recursos poéticos. Em "a alcipe, duplamente", o reconhecimento da relação transtextual com a obra de Pierre de Ronsard e da Marquesa de Alorna (Alcipe) se mostra fundamental para a construção do sentido do poema, num processo de transposição paródica da tradição literária.

Palavras-chave: Vasco Graça Moura; poesia portuguesa contemporânea; intertextualidade; transposição paródica.

Abstract: The present article's goal is to analyze elements of the poetry by Vasco Graça Moura (1942-2014) through the poem "a alcipe, duplamente", present in the anthology Poesia 2001/2005 (2006). A poet of classic lineage, Vasco Graça Moura has as a feature the abundant use of transtextual relations (according to Gérard Genette's definition) as a 
key element to the interpretation of his poems. In the analyzed poem, intertextuality (quote, allusion), architextuality and hypertextuality are highlighted as poetic resources. In "a alcipe, duplamente", the acknowledgement of the transtextual relation with works by Pierre de Ronsard and the Marquise of Alorna (Alcipe) is fundamental for the construction of the poem's meaning, in a process of parodic transposition of literary tradition.

Keywords: Vasco Graça Moura; contemporaneous Portuguese poetry; intertextuality; parodic transposition.

Recebido em 06 de outubro de 2017

Aprovado em 5 de janeiro de 2018

Vasco Graça Moura tem sido um dos nomes de destaque na literatura portuguesa contemporânea. O advogado, nascido em 1942 e falecido em 2014, destacou-se como poeta, ensaísta e tradutor. Além da profícua carreira literária, com mais de trinta livros publicados e traduções de nomes como Dante Alighieri e William Shakespeare -, Moura ocupou diversos cargos políticos após a Revolução dos Cravos (1974). Seu ativismo pós-1974 também se traduziu em militância na área cultural, dirigindo a emissora pública RTP2 e variadas fundações.

A crítica literária reconhece na poesia de Vasco Graça Moura um “sopro epicizante" (MOISÉS, 2008, p. 483), o qual se deve à recorrência de formas fixas consagradas e ao conteúdo intelectual de seus poemas (cf. MOISÉS, 2008, p. 483). A obra Poesia 2001/2005 é uma antologia publicada em 2006. A seção "currente calamo" apresenta poemas que unem o popular ao clássico, como bem indica a epígrafe: "um magusto poético no palácio fronteira" (MOURA, 2006, p. 121). "Magusto" é uma festa popular em que as famílias reúnem-se em torno da fogueira; "palácio fronteira" se refere ao Palácio dos Marqueses de Fronteira, em Lisboa. Construído no século XVII, o palácio foi residência de diversos nobres portugueses. Assim, ao lado de poemas com estrutura métrica rígida e referências eruditas, temos poemas que unem a forma clássica a temas prosaicos ("o magusto de ricardo reis") e jogos formais ("glosa libertina do mote desconstruído", "imitado de borges").

A expressão latina currente calamo significa "ao correr da pena", isto é, uma escrita sem grandes correções ou preocupações com o estilo. 
Ora, uma leitura breve dos poemas de Graça Moura basta para que o leitor desconfie dessa pretensa falta de cálculo: a busca deliberada e intensa pelo diálogo com outros poetas (Borges, Pessoa, Alcipe, Eugénio de Andrade) e a configuração formal dos versos, muitos deles seguindo esquemas métricos clássicos, indicam uma poética fruto de burilamento constante. Mais do que um despreocupado "correr da pena", o currente calamo de Moura remete a uma escrita marcada pelas mais diversas experimentações.

O Palácio Fronteira, mencionado na epígrafe, foi residência de Leonor Almeida Portugal de Lorena e Lencastre, a Marquesa de Alorna (1750-1839). Incentivadora de novos talentos, como Bocage e Herculano, a marquesa adotava em suas produções poéticas o nome árcade de Alcipe, numa referência à filha de Ares e Aglauro. Além de compor sonetos neoclássicos, a Marquesa de Alorna traduziu a Arte Poética de Horácio. Alcipe aparece em cinco poemas de "currente calamo": "a uma dona manuela júdice, recolhida no mosteiro de s. fernando pessoa a campo de Ourique", "a alcipe, duplamente", "glosa libertina do mote desconstruído", "a bacante" e "soneto de alcipessoa".

No poema "a uma dona manuela júdice, recolhida no mosteiro de s. fernando pessoa a campo de Ourique", o sujeito lírico afirma "que a não ser que me constipe / ou apanhe alguma gripe, / terei o maior prazer / em ir à casa de alcipe" (MOURA, 2006, p. 124). E é lá, nesse espaço, que se dá a construção do poema seguinte, "a alcipe, duplamente", no qual iremos focar a análise:

a alcipe, duplamente

As horas voadoras vão trazendo

$O$ instante fatal de uma partida

Alcipe

e ainda ecoa aqui, neste palácio,

$10(6,10)$

aquilo que, senhora, haveis escrito,

$10(6,10)$

lembrando-me, entre o bom e o bonito,

$10(6,10)$

coisas que vinham já do velho horácio.

$10(6,10)$

como ronsard eu quis beber no Lácio

$10(4,8,10)$

a vã dita galante de o ter dito

$10(6,10)$

a helena e a mignonne, com o fito

$10(6,10)$

de seduzi-las pelo cartapácio.

$10(4,8,10)$ 


$\begin{array}{ll}\text { e há sempre mais colegas nessa lida } & 10(6,10) \\ \text { sobretudo os que a foram escrevendo: } & 10(6,10) \\ \text { os poetas também sabem da vida } & 10(6,10) \\ \text { e as musas vivem disso, pois, correndo, } & 10(6,10) \\ \text { as horas voadoras vão trazendo } & 10(6,10) \\ \text { o instante fatal de uma partida } & 10(6,10) \\ & 10(6,10) \\ \text { as horas voadoras vão trazendo } & 10(6,10) \\ \text { o instante fatal de uma partida } & 10(6,10) \\ \text { e as musas vivem disso, pois, correndo, } & \\ & 10(6,10) \\ \text { os poetas também sabem da vida, } & 10(6,10) \\ \text { sobretudo os que a foram escrevendo, } & 10(6,10) \\ \text { e há sempre mais colegas nessa lida } & 10(4,8,10) \\ \begin{array}{l}\text { de seduzi-las pelo cartapácio, } \\ \text { a helena e a mignonne, com o fito }\end{array} & 10(6,10) \\ \text { e a vã dita galante de o ter dito. } & 10(6,10) \\ \text { como ronsard eu quis beber no lácio } & 10(4,8,10) \\ & \\ \text { coisas que vinham já do velho horácio, } & 10(6,10) \\ \text { lembrando-me, entre o bom e o bonito, } & 10(6,10) \\ \text { aquilo que, senhora, haveis escrito } & 10(6,10) \\ \text { e ainda ecoa aqui, neste palácio. } & 10(6,10)\end{array}$

O poema apresenta um mote dístico que vem a ser retomado nos demais versos (v. 13-16). Esse expediente era muito comum nas reuniões das academias árcades, em que sonetos eram improvisados glosando um mote prévio (cf. LIMA, 2007, p. 169-170). Vários poemas de "currente calamo" glosam motes, e é interessante perceber que a maioria dos autores resgatados por Moura é de extração clássica (Homero, Alcipe, o heterônimo pessoano Ricardo Reis, os brasileiros Ivo Barroso, Ivan Junqueira e Alexei Bueno). A relação entre a forma do poema e os procedimentos criativos das arcádias se confirma no mote apresentado, retirado do soneto alcipiano "A uma despedida":

As horas voadoras vão trazendo

$10(6,10)$

$\mathrm{O}$ instante fatal de uma partida,

$10(6,10)$

Que dos gostos ligeiros desta vida

$10(6,10)$

Um retrato funesto está fazendo.

$10(6,10)$ 
$\begin{array}{ll}\text { A sociedade amável entretendo } & 10(6,10) \\ \text { Esteve a paz (por pouco possuída); } & 10(6,10) \\ \text { Que em mágoa pela dura despedida } & 10(6,10) \\ \text { No aflito peito sinto ir convertendo. } & 10(6,10) \\ & 10(6,10) \\ \text { Com que horrores a pálida tristeza } & 10(6,10) \\ \text { Cobre o círculo breve dos meus anos, } & 10(6,10) \\ \text { Martiriza a sensível natureza! } & 10(6,10) \\ \text { Como havendo pesares tão tiranos, } & 10(6,10) \\ \text { E almas nobres, que adorna a singeleza, } & 10(6,10)\end{array}$ (ALORNA, 1844, p. 15).

O soneto "A uma despedida" foi composto pela Marquesa de Alorna quando o homem a quem amava, o poeta árcade Sebastião José Ferreira Barroco, partiu em viagem (cf. HORTA, 2012). O soneto de Alcipe, seguindo as regras neoclássicas, apresenta esquema rímico ABBA / ABBA/ CDC / DCD e é composto inteiramente por decassílabos heroicos (acento tônico na $6^{\mathrm{a}}$ e $10^{\mathrm{a}}$ sílabas poéticas). Nas estrofes, percebem-se o desconsolo e a dor causados pela separação. Também se destacam a fugacidade do tempo ("horas voadoras", "gostos ligeiros", "paz (por pouco possuída)", "círculo breve dos meus anos") e a inexorabilidade do fim ("instante fatal de uma partida", "retrato funesto", "dura despedida").

É aos versos de abertura desse soneto alcipiano que Vasco Graça Moura recorre dois séculos depois. O título, "a alcipe, duplamente", remete à estrutura dupla do poema, em que são expostos dois sentidos de leitura: as quatro primeiras estrofes formam um soneto; as quatro últimas resultam da leitura invertida dos versos anteriores. A indicação do espelhamento é a repetição do mote alcipiano "As horas voadoras vão trazendo / O instante fatal de uma partida". Essa forma invertida de soneto também é chamada de soneto-labirinto, estrutura que permite a "leitura retrógrada" (LIMA, 2007, p. 188).

Além da referência à Alcipe, a métrica filia o poema de Moura à estética clássica. O ritmo cadenciado dos versos é dado pela repetição de decassílabos heroicos e sáficos (tônica na $4^{\mathrm{a}}, 8^{\mathrm{a}}$ e $10^{\mathrm{a}}$ sílabas poéticas). $\mathrm{O}$ esquema rímico do soneto, em seu sentido corrente de leitura, é ABBA / ABBA / CDC / DDC. Na diferença entre os tercetos finais de Alcipe (DCD) e de Moura (DDC), podemos entrever a marca do novo: "a alcipe, duplamente" resgata, glosa e modifica o texto neoclássico. 
Na primeira estrofe, o sujeito lírico se dirige a Alcipe, a quem o poema é dedicado. $\mathrm{O}$ verso de abertura prescinde de inicial maiúscula, rompendo com as hierarquias, e insere o poema num discurso já em andamento. A voz do sujeito lírico não quebra o silêncio, mas faz parte de algo que já está em curso, "de discursos anteriores" (HUTCHEON, 1991, p. 166). Como Foucault, o sujeito lírico de Moura é envolvido pela palavra: "no momento de falar uma voz sem nome me precedia há muito tempo: bastaria, então, que eu encadeasse, prosseguisse a frase [...]. Não haveria, portanto, começo" (FOUCAULT, 2006, p. 5). A adoção da inicial minúscula no primeiro verso, pois, vincula o cantar contemporâneo de Vasco Graça Moura ao cantar árcade de Alcipe. Outra marca linguística do poema como continuidade (e não enquanto começo) é a conjunção aditiva "e", a qual proporciona ao leitor a impressão de que o sujeito lírico já estava em meio a um diálogo com Alcipe. Os primeiros versos, como que escritos in media res, revelam em Moura o desejo foucaultiano "de se encontrar, logo de entrada, do outro lado do discurso" (FOUCAULT, 2006, p. 6).

As palavras escritas outrora por Alcipe ainda ecoam, ou seja, a palavra poética permanece (v. 1-2). O eco da poesia alcipiana remete o sujeito lírico aos valores da estética clássica: o bom, o belo, o verdadeiro (v. 3), valores preconizados por Horácio (v. 4) em sua Arte poética, obra traduzida pela Marquesa de Alorna. O sujeito lírico está em um palácio (v. 1), muito provavelmente o Palácio Fronteira, mencionado na epígrafe de "currente calamo" e "casa de alcipe" (MOURA, 2006, p. 124). A presença do sujeito lírico nesse palácio indica, mais uma vez, o alinhamento de sua poética à estética clássica - o que se confirma se verificarmos os autores que o poeta traduziu: Dante, Petrarca, Villon. É nesse lugar que o sujeito lírico pós-moderno de Graça Moura se situa: num espaço do passado, palácio clássico, local em que os versos árcades de Alcipe ainda ressoam.

Na segunda estrofe, o sujeito lírico deseja ter a felicidade, embora vã, de seduzir por meio de seu fazer poético, a exemplo de Pierre de Ronsard (1524-1585), outra referência clássica. No Lácio, região italiana de onde se originaram o latim e, por extensão, a língua portuguesa, o sujeito lírico quisera fazer cartapácios de poemas tais como os do francês Ronsard. Poeta renascentista traduzido por Vasco Graça Moura, Ronsard compôs os "Sonetos a Helena" (1578), série de onze poemas, e a "Ode a 
Cassandra" (RONSARD, 1972, p. 94-95). É a esses poemas que o sujeito lírico se refere intertextualmente (v. 7).

No primeiro quarteto e no terceto que fecha o soneto de Ronsard, "Quando fores bem velha", lê-se:

$\begin{array}{ll}\text { Quando fores bem velha, à noite, à luz da vela } & 12(6,12) \\ \text { Junto ao fogo do lar, dobando o fio e fiando, } & 12(6,12) \\ \text { Dirás, ao recitar meus versos e pasmando: } & 12(6,12) \\ \text { Ronsard me celebrou no tempo em que fui bela. } & 12(6,12) \\ & \\ \text { [...] } & 12(6,12) \\ \text { Chorando o meu amor e o teu cruel desdém. } & 12(6,12) \\ \text { Vive sem esperar pelo dia que vem; } & 12(6,12) \\ \text { Colhe hoje, desde já, colhe as rosas da vida. } & \\ \text { (RONSARD, 1578). }\end{array}$

Em versos alexandrinos, Ronsard poetiza sobre o amor, a brevidade da vida (vita brevis) e insta a amada a colher o dia (carpe diem), temas que são retomados pela estética neoclássica. Reconhecemos, no recado do amante à amada, o diálogo com o soneto árcade de Alcipe, no qual o sujeito lírico lamenta a passagem das horas voadoras e a fugacidade dos prazeres da vida. Na "Ode a Cassandra", os mesmos temas aparecem: "Oh, amor [Mignonne]! Vê quão depressa / Fenecendo, a rosa cessa / De ser bela e ser louçã! [...] Meu conselho é, pois, amor, / Que, enquanto na vida em flor, / Encantos possam sobrar-te: / Colhe, colhe a mocidade, / Pois como à rosa a idade / Da beleza há de privar-te" (RONSARD, [ s./d.], p. 282).

Nos dois tercetos, o sujeito lírico afirma que, como ele e Ronsard, há outros poetas na lida do fazer poético e da conquista (conquista amorosa? Conquista do leitor?) por meio da palavra (v. 9-10). Ele sentencia: os poetas vivem, poetizam o vivido e, por isso, sabem da vida (v. 11). As musas, por sua vez, vivem de inspirar os poetas a escrever o amor vivido antes que as horas voem e o fim chegue (v. 12-14), pois a vida é breve (vita brevis). A imagem da brevidade e a ânsia por aproveitar o tempo presente (carpe diem) são construídas pela repetição do mote alcipiano ao fim do primeiro soneto.

Tem início, agora, a leitura espelhada, procedimento que reordena a sintaxe dos versos. De acordo com Lotman, "a estrutura fundamental do verso é a repetição" (1978, p. 236) e, portanto, toda repetição pode ser semantizada. A repetição espelhada no soneto labiríntico não é 
idêntica, mas “invertida” (KIERKEGAARD, 2009, p. 74) e diferencial, uma vez que as variações sintáticas e semânticas verificadas na segunda leitura fazem aflorar novos sentidos. O sujeito lírico, no diálogo invertido com Alcipe, repete o mesmo "de todas as maneiras possíveis" (KIERKEGAARD, 2009, p. 76).

No primeiro terceto, vemos que as musas, agora, vivem da passagem das horas (v. 17). A poesia se ocupa da vida (v. 18), e um dos maiores motivos inspirados pelas musas é a transitoriedade da existência, como os temas clássicos vita brevis e carpe diem demonstram. Os poemas que dialogam intertextualmente com a obra de Moura trazem essa temática: em "A uma despedida", Alcipe está desconsolada ao ver o amado partir; no soneto "Quando fores velha", de Ronsard, o sujeito lírico imagina a sua amada, já idosa, lamentando tê-lo desprezado na juventude; na "Ode a Cassandra", o sujeito lírico convida a amada a colher a mocidade, pois a beleza findará.

Conforme a teoria de Lotman, "as repetições fônicas podem estabelecer ligações complementares entre as palavras” (1978, p. 192). Assim, os vocábulos sobre os quais o acento tônico recai se recobrem de significação especial; é o que se verifica na repetição do /i/ tônico em "seduzi-las" (v. 8 e v. 21) e "lida" (v. 9 e v. 20). Ao ligar os sentidos desses dois vocábulos, conclui-se que a lida do poeta é, pois, seduzir, encantar e conquistar o interlocutor via discurso. Os poetas que mais sabem da vida são os que sobre ela escrevem (v. 18-19). E viver e poetizar a vida implica amor: "e há sempre mais colegas nessa lida / de seduzi-las pelo cartapácio" (v. 20-21). A exemplo do renascentista Ronsard, o sujeito lírico quis beber no Lácio os valores ditados por Horácio, lembrando-se do que Alcipe escrevera (v. 24-26). Ao contrário das horas e da vida, transitórias, a palavra poética permanece e segue a ressoar (v. 27-28).

As rimas, fenômenos semânticos que correlacionam os significados das palavras (cf. LOTMAN, 1978, p. 215-216), estabelecem equivalências entre os vocábulos e criam arquissemas (cf. LOTMAN, 1978, p. 251-252). Desse modo, temos correlação semântica entre palácio (v. 1, 28), já (v. 4, 25), horácio (v. 4, 26), lácio (v. 5, 9), cartapácio (v. $8,21)$, vocábulos que remetem o leitor ao contexto clássico e ao fazer poético; os verbos no gerúndio - escrevendo (v. 10, 19), correndo (v. 12, 17), trazendo (v. 13, 16) - expressam a ideia de processo em curso e de passagem. Também nos parece significativa a identidade sonora entre lida 
(v. 9, 20), vida (v. 11, 18) e partida (v. 14, 16): a vida do poeta é poetizar contra o tempo, cantar o dia antes que o instante fatal da partida chegue.

Ao operar na lógica inversa, o soneto-labirinto altera a estrutura do soneto tradicional, na qual o mote - chave de ouro - "fecha" o poema e, de certa forma, direciona a interpretação. Na inversão pós-moderna perpetrada por Moura o mote não fecha, mas inicia o soneto espelhado, deixando os últimos versos em liberdade. A ausência da chave de ouro permite que a palavra poética de Alcipe ecoe indefinidamente (v. 28). Por meio da imagem final das palavras da Marquesa de Alorna a ecoar no palácio, o poeta reflete, duplamente, sobre o poder de conquista e sedução exercido pela arte da palavra e sobre a permanência da palavra poética diante da fugacidade da vida.

A análise do poema evidencia que "a alcipe, duplamente" é uma teia de relações transtextuais. Segundo Genette, a transtextualidade ou transcendência textual do texto é o processo pelo qual um texto se encontra "em relação, manifesta ou secreta com outros textos" (GENETTE, 2006, p. 7). Dentre as cinco subcategorias transtextuais propostas por Genette, destacam-se no poema de Vasco Graça Moura a inter, a arqui e a hipertextualidade.

Genette alarga o conceito de intertextualidade inaugurado por Mikhail Bakhtin e Julia Kristeva, definindo-a como a "efetiva presença de um texto no outro por meio de citação, plágio e alusão" (GENETTE, 2006, p. 8). São intertextuais, portanto, as citações ao soneto alcipiano, as referências a Ronsard e seus poemas e a menção a Horácio. O intertexto exerce papel significativo na leitura do poema, pois a perenidade da palavra poética, proposta pelo sujeito lírico nos últimos versos, é atestada pelo diálogo vivo entre a produção de Horácio, Ronsard e Alcipe. As citações e alusões presentes no poema - o que Guimarães chama de "referências cultas" (1983, p. 94) - podem ser entendidas como um traço pós-moderno não de ruptura, mas de vínculo com o passado, numa recriação paródica sem viés corrosivo. As relações intertextuais entre a obra de Vasco Graça Moura e seus antecessores tornam "todos [...] contemporâneos uns dos outros" (AMARAL, 2004, p. 13). Em Alcipe, Ronsard e Horácio, Moura descobriu "algum ramo perdido da árvore genealógica” (AMARAL, 2004, p. 13).

Vasco Graça Moura constrói sua imagética por meio da citação de nomes, criando um novo espaço intertextual formado pelas associações que esses nomes sugerem (cf. GUIMARÃES, 1983, p. 94). 
Para Condinho (1995, p. 239), a panóplia erudita de citações, alusões e utilizações das mais diversas obras, encadeadas num todo coerente, é uma característica da poética de Moura. As imagens no poema "a alcipe, duplamente" constroem-se pelo recurso da citação e pela referencialidade intertextual (HUTCHEON, 1991, p. 200). O intertexto referencial menção a nomes de autores, títulos de obras, personagens, etc. - não é um expediente gratuito, mas indicação, ao leitor, de uma determinada forma de ler o texto. Os referentes remetem a intertextos específicos; assim, o mote de Alcipe, a menção a Ronsard e a Horácio e o emprego do soneto como forma poética são pistas interpretativas que o sujeito lírico fornece ao leitor. Estamos diante de uma obra em que a intertextualidade "desempenha uma função constitutiva" (TODOROV, 1980, p. 61).

A arquitextualidade é definida por Genette como a relação entre um texto e seu gênero, a qual "orienta e determina o 'horizonte de expectativa' do leitor e, portanto, da leitura da obra" (GENETTE, 2006, p. 12). O arquitexto determina as "regras do jogo" (COMPAGNON, 2006, p. 158). A relação arquitextual entre o poema de Vasco Graça Moura e a forma soneto contribui para o processo interpretativo da obra. O emprego do mote e do soneto-labirinto, estrutura poética clássica, une a lírica pósmoderna de Moura à dos seus antecessores - insere-o na teia do discurso, encadeia sua voz à dos predecessores. Com seu soneto-labirinto, Vasco Graça Moura inscreve-se no grupo de "colegas" (v. 9 e 20) dedicados à arte da palavra.

A maior transformação - ou ousadia, por assim dizer - realizada por Moura é a repetição dos versos da Marquesa de Alorna, retirando-os do contexto original. Trata-se da relação hipertextual, em que um texto "brota" (GENETTE, 2006, p. 12) do outro. O hipertexto deriva de um hipotexto preexistente e o transforma. A retomada dos versos de Alcipe é uma relação hipertextual que se estabelece por meio da "paródia séria" (GENETTE, 2006, p. 21) ou "transposição" (GENETTE, 2006, p. 23). "a alcipe, duplamente" é um texto paródico, marcado pela "ocorrência de uma síntese bitextual em que o antigo se incorpora ao novo pela sobreposição das estruturas" (cf. HUTCHEON, 1985, p. 50). A repetição dos versos de Alcipe não apenas liga a poética dos dois autores, mas também estabelece a diferença. A repetição é diferencial (ALMEIDA, 2001) e multíplice: ainda que as diferenças sejam mínimas, alguma transformação ocorre; sempre há "algo de novo" (KIERKEGAARD, 2009 , p. 51). A paródia transposicional, por si só, não é expediente pós- 
moderno; o traço que insere a poética de Moura no que se tem chamado pós-modernidade é a diferença de tom da transposição realizada. Como Bakhtin (1993, p. 325) aponta, na Idade Média os textos sacros eram parodiados de forma jocosa e lúdica; na era pós-moderna da colagem, das releituras e recombinações, a transposição parodística se dá de forma "séria" (GENETTE, 2006, p. 21), utilizando-se de hipotextos consagrados para questioná-los e produzir textos novos.

Ao dialogar com os clássicos, Vasco Graça Moura põe em xeque a noção de uma pós-modernidade em confronto com os paradigmas anteriores. Nas palavras do poeta Fernando Pinto do Amaral,

a atitude dos clássicos está cada vez mais na ordem do dia, sobretudo tendo em conta um problema quanto a mim central da nossa época - refiro-me à relativa dissolução do valor do novo e do original [...]: de facto, enquanto cada uma das décadas do nosso século [...] procurou sempre, de certo modo, contestar ou superar ou romper com paradigmas estéticos da década anterior (veja-se o neo-realismo dos anos 40 contra os presencistas, a poesia lírica ou idealista ou surrealista dos anos 50 contra os neorealistas, o tardo-modernismo experimentalista dos anos 60 contra o existencialismo dos de 50, ou ainda o regresso ao quotidiano e à experiência dos anos 70 contra as vanguardas de 60), vivemos hoje um momento inédito, já que, em geral, os poetas revelados a partir da década de 80 não pretenderam romper com os anteriores (fossem eles quais fossem), recusando a lógica da permanente ruptura e a ideia de negação radical. (2004, p. 12)

Nessa lógica, já não existe ruptura: o diálogo criativo com a tradição engendrado por Vasco Graça Moura insere sua poética em uma continuidade, na tradição do discurso poético. Ainda assim, sua obra não é neoclássica ou árcade: é pós-moderna, trazendo elementos do passado e transpondo-os parodisticamente a novos contextos. Segundo Paz, "aquele que sabe ser pertencente a uma tradição implicitamente já se sabe diferente dela" (1984, p. 25). Vasco Graça Moura tem essa consciência, e é ela que lhe dá a liberdade de se valer dos recursos formais clássicos para poetizar sobre os mais diversos temas - Moura é um dos poetas que sabem da vida (v. 11, 18). Seu processo de transposição paródica questiona a noção de originalidade e mostra que "quem escreve ou quem lê [no contexto da pós-modernidade] está disposto a aceitar que qualquer produção literária - por mais inovadora que se apresente - se integra 
numa infinita rede intertextual cujo princípio original ou cujo fim último não somos nem seremos capazes de conhecer" (AMARAL, 2004, p. 12). "currente calamo" apresenta uma recriação propositiva do hipotexto alcipiano na "glosa libertina do mote desconstruído" (MOURA, 2006, p. 127). Esse poema, que sucede "a alcipe, duplamente", decompõe o mote de Alcipe e o redistribui. Na glosa libertina, já não há espaço para os temas clássicos; o tema é prosaico e, até mesmo, erótico:

glosa libertina do mote desconstruído

As horas voadoras vão trazendo

O instante fatal de uma partida

Alcipe

vinde ouvir voltas a mote

$7(3,7)$

pelas horas voadoras

$7(3,7)$

por isso minhas senhoras

$7(2,7)$

aligeirai o decote

$7(4,7)$

mostrai prendas sedutoras

$7(3,7)$

e dai-me a ver nesse instante

$7(4,7)$

em fatal arremetida

$7(3,7)$

o que em vós é mais arfante

$7(3,7)$

e onde pousa um diamante

$7(3,7)$

a pregar-vos a partida.

$7(3,7)$

fosse eu tão puro carbono

$7(4,7)$

rodeado de esmeraldas

$7(3,7)$

e de repente no sono

$7(4,7)$

simularia abandono

$7(4,7)$

pra rolar dentro das fraldas.

$7(4,7)$

ai de mim, todas as horas

$7(3,7)$

nessa macia descida

$7(4,7)$

me trariam de seguida

$7(3,7)$

só poréns e mais emboras

$7(3,7)$

de me pôr a alma partida.

$7(3,7)$

sendo assim curta a viagem

$7(4,7)$

para quem tanto imagina

$7(4,7)$

ficaria da aterragem

$7(3,7)$

rasto e tacto de uma imagem

$7(3,7)$

permanente na retina.

$7(3,7)$

e assim eu a irei retendo

$7(3,7)$ 


$\begin{array}{ll}\text { quando as horas de corrida } & 7(3,7) \\ \text { voadoras vão trazendo } & 7(3,7) \\ \text { o instante fatal dizendo } & 7(4,7) \\ \text { ser já tempo de partida. } & 7(3,7) \\ \text { (MOURA, 2006, p. 127). } & \end{array}$

Partimos do Palácio Fronteira ao magusto poético. Divididos em três décimas, os versos apresentam sete sílabas poéticas (redondilha maior, recorrente na poética de Garcia de Resende e Camões) e esquema rímico misto. O dístico alcipiano novamente serve de epígrafe, mas já não retorna como refrão: fragmenta-se e se embaralha, tendo cada uma de suas partículas inserida em novos contextos linguísticos. A utilização dos verbos na segunda pessoa do plural, traço arcaizante, confere tom elevado a um poema de tema prosaico: "aligeirai o decote / mostrai prendas sedutoras" (v. 4, e 5). As pedras preciosas - esmeraldas, diamantes - remetem à nobreza. As joias se ligam à materialidade, ao corpo da mulher, ao desejo - o diamante, puro carbono, a rolar dentro dos trajes de baixo se possível fosse (v. 9-15). O prazer carnal é momentâneo e pode levar a crises, a adversidades, a concessões (v. 17-20), tal como o amor entre a Marquesa de Alorna e Sebastião José Ferreira Barroco. Nos versos da glosa libertina de Moura, repercute a primeira estrofe de "A uma despedida", reflexão sobre o caráter fugidio dos gostos ligeiros da vida - neles incluído o amor.

As três décimas se encerram com a palavra "partida". No fim da primeira estrofe, o sujeito lírico afirma haver um diamante pousado a "pregar uma partida", pregar uma peça em suas interlocutoras (v. 9-11). Os verbos no imperativo conclamam as senhoras a se aproximar do sujeito lírico para ouvi-lo e seduzi-lo. Ocorre uma inversão do processo poetizado em "a alcipe, duplamente", quando era o poeta a seduzir pelo cartapácio. Na segunda estrofe, a predominância de verbos no futuro do pretérito do indicativo sugere imaginação, conjecturas, hipóteses, desejos. Ao fim da estrofe, o sujeito lírico se vale do adjetivo "partida" para indicar como se sentiria sua alma ao deparar-se com as consequências do relacionamento amoroso. A fugacidade do encontro é contornada pela imaginação e pelos sentidos (v. 21-25), única forma de retê-lo no espaço da memória ao chegar o "tempo de partida" (v. 30).

A operação de transposição paródica iniciada em "a alcipe, duplamente" se completa e se soma ao processo de rebaixamento, "transferência ao plano material e corporal, o da terra e do corpo na sua 
indissolúvel unidade, de tudo que é elevado, espiritual, ideal e abstrato" (BAKHTIN, 1993, p. 17). Do Palácio Fronteira, do Lácio, do mundo de Horácio, Ronsard e Alcipe, o leitor é conduzido ao magusto, à festa, ao mundo pós-moderno, à decomposição e recomposição das formas clássicas - e isso não se configura como negação ou demérito para com os autores clássicos, mas diálogo, repetição, instauração do novo a partir do velho. Vasco Graça Moura confirma, em sua poética, que as palavras de Horácio, Ronsard e Alcipe ainda ecoam aqui, na contemporaneidade.

\section{Referências}

ALMEIDA, L. P. Notas sobre a Gjentagelsen kierkegaardiana, 2001. Disponível em: $<$ http://www.ifen.com.br/artigos/leo-2001.htm>. Acesso em: 10 jun. 2012.

ALORNA, Marquesa de. Obras poéticas de D. Leonor de Almeida Portugal Lorena e Lencastre. Lisboa: Imprensa Nacional, 1844. Disponível em: <https://books.google.com.br/books?id=1pkfAQAAIAAJ\&pg= PA15\&lpg $=$ PA15\&dq $=\mathrm{a}+$ um a + despedida + marquesa + de + alorna\&sourc e=bl\&ots=bZqjhdN3z6\&sig=dSEfTilQTofugEtFAFJ01EwhpeM\&hl=ptBR\&sa $=$ X\&ved=0ahUKEwisk-ySILDWAhXE2yYKHRCMAAsQ6AE IRT $A H \# \mathrm{v}=$ onepage $\& \mathrm{q}=\mathrm{a} \% 20 \mathrm{uma} \% 20$ despedida $\% 20$ marquesa $\% 20 \mathrm{de} \%$ 20alorna\&f=false $>$. Acesso em: 18 set. 2017.

AMARAL, F. P. O legado clássico na poesia contemporânea. In: FERREIRA, José Ribeiro; DIAS, Paula Barata (Coord.). Fluir Perene: a cultura clássica em escritores portugueses contemporâneos. Coimbra: Universidade de Coimbra, 2004. p. 9-15.

BAKHTIN, M. A cultura popular na Idade Média e no Renascimento: o contexto de François Rabelais. 2. ed. Tradução de Yara Frateschi Vieira. São Paulo: Hucitec, 1993.

COMPAGNON, A. O demônio da teoria: literatura e senso comum. Tradução de Cleonice Paes Barreto Mourão e Consuelo Fortes Santiago. Belo Horizonte: UFMG, 2006.

CONDINHO, L. O concerto campestre: recensão. Colóquio/Letras, Lisboa, Fundação Calouste Gulbenkian, n. 135/136, p. 239-240, jan. 1995. Disponível em: $<$ http://coloquio.gulbenkian.pt/bib/sirius.exe/issu eContentDisplay? $\mathrm{n}=135 \& \mathrm{p}=239 \& \mathrm{o}=\mathrm{p}>$. Acesso em: 22 jun. 2014. 
FOUCAULT, M. A ordem do discurso: Aula inaugural no Collège de France, pronunciada em 2 de dezembro de 1970. 14. ed. Tradução de Laura Fraga de Almeida Sampaio. São Paulo: Loyola, 2006.

GENETTE, G. Palimpsestos: a literatura de segunda mão. Tradução de Luciene Guimarães e Maria Antônia Ramos Coutinho. Belo Horizonte: Faculdade de Letras/UFMG, 2006. Disponível em: $<$ http://pt.scribd. com/doc/46591105/GENETTE-Gerard-Palimpsestos>. Acesso em: 26 mar. 2014.

GUIMARÃES, F. A variação dos semestres deste ano; 365 versos, seguido de A escola de Frankfurt: recensão. Colóquio/Letras, Lisboa, Fundação Calouste Gulbenkian, n. 71, p. 94-95, jan. 1983. Disponível em: $<$ http:// coloquio.gulbenkian.pt/bib/sirius.exe/issueContentDisplay? $=71 \& \mathrm{p}=$ 94\&o=p > . Acesso em: 22 jun. 2014.

HORTA, M. T. As luzes de Leonor: a marquesa de Alorna, uma sedutora de anjos, poetas e heróis. Alfragide: Dom Quixote, 2012.

HUTCHEON, L. Uma teoria da paródia: ensinamentos das formas de arte do século XX. Tradução de Teresa Louro Pérez. Lisboa: Edições 70, 1985.

HUTCHEON, L. Poética do pós-modernismo: história, teoria, ficção. Tradução de Ricardo Cruz. Rio de Janeiro: Imago, 1991.

KIERKEGAARD, S. A repetição: um ensaio em psicologia experimental por Constantin Constantius. Tradução de José Miranda Justo. Lisboa: Relógio D’Água, 2009.

LIMA, R. L. M. A forma soneto. Maceió: UFAL, 2007.

LOTMAN, I. A estrutura do texto artístico. Tradução de Maria do Carmo Vieira Raposo e Alberto Raposo. Lisboa: Estampa, 1978.

MOISÉS, M. A literatura portuguesa. 35. ed. São Paulo: Cultrix, 2008.

MOURA, V. G. currente calamo. In: . Poesia 2001/2005. Lisboa: Quetzal, 2006. p. 119-161.

PAZ, O. Os filhos do barro: do romantismo à vanguarda. Tradução de Olga Savary. Rio de Janeiro: Nova Fronteira, 1984.

RONSARD, P. Ode a Cassandra. O livro de ouro da poesia da França. Tradução de R. Magalhães Jr. Rio de Janeiro: Tecnoprint, 1972. p. 282. 
RONSARD, P. Quand vous serez bien vieille / Quando fores bem velha. Tradução de Guilherme de Almeida. 1578. Disponível em: <http:// antoniocicero.blogspot.com.br/2009/03/pierre-de-rondard-quand-vousserez-bien.html>. Acesso: 18 set. 2017.

TODOROV, T. Simbolismo e interpretação. Tradução de Maria de Santa Cruz. Lisboa: Edições 70, 1980. 